\title{
Behavior of Reduction Precipitation of Nickel Adsorbed on the Surface of Sulfur-Impregnated Carbonaceous Cotton
}

\author{
Masaya Iguchi and Takaaki Wajima \\ Department of Urban Environment System, Chiba University.
}

\begin{abstract}
In this study, reduction treatment was applied to nickel adsorbed on a sulfur-impregnated carbonaceous cotton prepared using sulfide aqueous solutions, and the precipitation behavior of nickel was determined. Two types of sulfide solutions, $\mathrm{K}_{2} \mathrm{~S}$ and $\mathrm{Na}_{2} \mathrm{~S}$, were used for preparation of the sulfur-impregnated adsorbent. A cotton immersed in sulfide solution was pyrolyzed in an electric tubular furnace to obtain the fibrous adsorbent. Nickel was adsorbed on the surface of the adsorbent by passing a $10 \mathrm{mM} \mathrm{Ni}\left(\mathrm{NO}_{3}\right)_{2}$ solution through the obtained adsorbent, and the fibrous adsorbent adsorbed nickel was heated in $\mathrm{N}_{2}$ atmosphere using an electric tubular furnace as reduction treatment. The adsorbents on each process were analyzed by X-ray diffraction (XRD) and observed by scanning electron microscope (SEM), respectively, and the effects of sulfide type, concentration and reduction temperature on the precipitation behavior of nickel adsorbed on the sulfur-impregnated cotton was examined. The adsorption amount of the adsorbent obtained using $1.0 \mathrm{M} \mathrm{Na}_{2} \mathrm{~S}$ was higher than that using $1.0 \mathrm{M} \mathrm{K}_{2} \mathrm{~S}$. From the analysis of adsorption isotherms using Langmuir and Freundlich model, the Langmuir model matched the data better than the Freundlich model for both adsorbents, and maximum adsorption capacity calculated from the Langmuir isotherm model for the adsorbent obtained using $\mathrm{Na}_{2} \mathrm{~S}$ was $0.43 \mathrm{mmol} / \mathrm{g}$, which was higher than that using $\mathrm{K}_{2} \mathrm{~S}(0.27 \mathrm{mmol} / \mathrm{g})$. $\mathrm{Ni}_{3} \mathrm{~S}_{2}$ was precipitated on the adsorbent prepared using $1.0 \mathrm{M} \mathrm{K}_{2} \mathrm{~S}$ by reduction treatment at more than $800{ }^{\circ} \mathrm{C}$, while metallic nickel was precipitated on the adsorbent prepared using $0.5 \mathrm{M} \mathrm{Na}_{2} \mathrm{~S}$ by reduction treatment at more than $800{ }^{\circ} \mathrm{C}$. The amount and size of the precipitated particles increased with increasing the reduction temperature.
\end{abstract}

Key words: sulfur-impregnated carbonaceous cotton, nickel removal, reduction treatment

\section{INTRODUCTION}

Water pollution caused by heavy metals is one of the environmental problems all over the world because heavy metal ions are harmful to living organisms even at low concentrations. Heavy metal pollution is mainly caused by wastewater from agriculture using fertilizer and insecticide, and industry for plating, tanning, chemicals, mining and petroleum refining. Heavy metal ions should be removed from these wastewater before discharging to natural water.

Present methods for removing heavy metal include coagulation sedimentation [1], ion exchange [2, 3], membrane filtration $[4,5]$ and adsorption method $[6$, 7]. Among them, the adsorption method is known to be able to remove heavy metals efficiently with a simple process even at low concentration. The adsorption method mainly depends on the performance and price of the adsorbent. Therefore, a high-performance and inexpensive heavy metal adsorbent was studied, such as natural zeolite [8], waste biomass [9], modified waste biomass [10] and activated carbon [11].

In previous studies, sulfur-impregnated adsorbent with high affinity for heavy metal ions can be prepared from coal and waste biomass using pyrolysis [12 - 20] because sulfur has a high affinity for heavy metal ions (Pearson's rule) [21, 22]. Moreover, nickel ion can be recovered from nickel-plating waste solution using sulfur-impregnated rice straw [16]. Nickel is one of rare metals used in various fields of industry, such as stainless steel, alloy steel, nonferrous alloy, superalloy and plating. Annual production of nickel is about 2.1 million ton all over the world, and its reserves are ubiquitous, $25.7 \%$ in Australia and $16.2 \%$ in Brazil [23]. Industrial countries, such as Japan, are required to secure nickel resources to produce the advanced materials.

In this study, we focused on reduction treatment for recovering nickel adsorbed on sulfur-impregnated

Corresponding Author: Masaya Iguchi, Department of Urban Environment System, Chiba University, 1-33 Yayoi-cho Inage-ku Chiba 263-8522 Japan, +819012984637 
adsorbent. A fibrous heavy metal adsorbent was prepared from cotton, which is a fibrous biomass made of cellulose, by sulfur-impregnation and adsorbed nickel ion from aqueous solution. Precipitation of nickel adsorbed on the adsorbent by reduction treatment was performed to recover the nickel metal from wastewater efficiently. The effects of sulfide type, concentration and reduction temperature on nickel precipitation after reduction of sulfur-impregnated adsorbent was investigated

\section{EXPERIMENT}

\section{Preparation of sulfur-impregnated carbonaceous cotton}

Sulfur-impregnated carbonaceous cotton was prepared by the method referred in a previous paper [21]. Experimental apparatus for preparation and reduction treatment is shown in figure 1. The preparation and reduction treatment were performed using an electric tubular furnace under $\mathrm{N}_{2}$ atmosphere. A transparent quartz tube on the furnace is $45 \mathrm{~mm}$ inside diameter with $0.75 \mathrm{~m}$ in length. Cotton was immersed in $\mathrm{Na}_{2} \mathrm{~S}$ and $\mathrm{K}_{2} \mathrm{~S}$ solutions with $0.5 \mathrm{M}$ and $1.0 \mathrm{M}$, then each immersed cotton set in the tube. Before pyrolysis, $\mathrm{N}_{2}$ gas was injected into the tube for $30 \mathrm{~min}$ at a rate of $1.0 \mathrm{~L} / \mathrm{min}$ to replace the air to $\mathrm{N}_{2}$ gas in the tube, and the cotton were pyrolyzed using electric tubular furnace at $400{ }^{\circ} \mathrm{C}$ for 1 hour in furnace with $\mathrm{N}_{2}$ gas flow at a rate of $1.0 \mathrm{~L} / \mathrm{min}$. After pyrolysis, the residue was cooled to room temperature in a tube with keeping $\mathrm{N}_{2}$ flow, and washed with distilled water to remove impurities to obtain the sulfur-impregnated cotton.

\section{Nickel adsorption}

For investigating adsorption isotherm of nickel, the fibrous adsorbents prepared using 1.0 $\mathrm{M} \mathrm{Na}_{2} \mathrm{~S}$ and 1.0 $\mathrm{M} \mathrm{K}_{2} \mathrm{~S}$ were grounded to under $250 \mu \mathrm{m}$. $0.1 \mathrm{~g}$ of powder

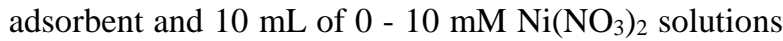
were mixed in a centrifuge tube using shaker for 24 hours. After shaking, the tube was centrifuged and nickel concentration in the supernatant was measured by atomic absorption spectrometer (AAS, AAnalyst 200, Parkin Elmer) and $\mathrm{pH}$ of the supernatant was measured by $\mathrm{pH}$ meter (C-73 AS ONE).

\section{Reduction treatment}

Nickel adsorbed cotton was prepared using $10 \mathrm{mM}$ $\mathrm{Ni}\left(\mathrm{NO}_{3}\right)_{2}$ solution to saturate the adsorbent with nickel ion. For a column experiment, glass wool and 0.3 to 0.5 $\mathrm{g}$ of each sample were filled in a $30 \mathrm{~mL}$ syringe in this order, and $10 \mathrm{~mL}$ of $10 \mathrm{mM}$ nickel nitrate solution was passed through the syringe for 8 times to prepare the nickel saturated adsorbent. The fibrous adsorbent filter after adsorption was washed for removal of nickel on the surface of the filter (not adsorbed with filter) and then dried at $50{ }^{\circ} \mathrm{C}$. After saturating the fibrous adsorbent with nickel ions, the adsorbent was treated by reduction to precipitate nickel on the surface of adsorbent to recover of the nickel metal.

The nickel saturated fibrous adsorbent was put in a ceramic board and installed in a transparent quartz tube of $45 \mathrm{~mm}$ inside diameter with $0.75 \mathrm{~m}$ in length. Before reduction, $\mathrm{N}_{2}$ gas was injected into the tube for $30 \mathrm{~min}$ at a rate of $1.0 \mathrm{~L} / \mathrm{min}$ to replace the air to $\mathrm{N}_{2}$ gas in the tube. Reduction treatment was performed in an electric tubular furnace at $400-1000{ }^{\circ} \mathrm{C}$ for $1 \mathrm{~h}$ with $\mathrm{N}_{2}$ gas flow at a rate of $1.0 \mathrm{~L} / \mathrm{min}$. After heating, the adsorbent after treatment was cooled to room temperature in a tube, while flowing $\mathrm{N}_{2}$ gas to obtain the adsorbent after reduction.

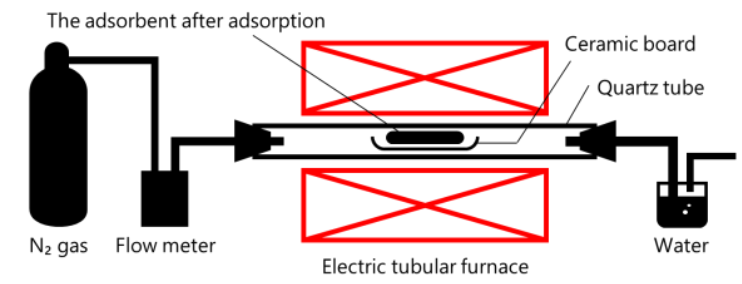

Figure 1 Experimental apparatus for production and reduction of adsorbent.

\section{Characterization}

The crystalline phases in the adsorbent before adsorption, after adsorption and reduction were identified using X-ray diffraction (XRD) with monochromated $\mathrm{CuK} \alpha$ radiation (MiniFlex600, Rigaku, Japan). The surface of the adsorbent before adsorption, after adsorption and reduction were observed using scanning electron microscope (SEM) (JSM-6510A, JEOL). The elements of each samples were analyzed using energy dispersive X-ray spectrometer (EDS) (EX94300S4L1Q, JEOL).

\section{RESULT AND DISCUSSION}

\section{Adsorption isotherm of sulfur-impregnated carbonaceous cotton}

Figure 2 shows the adsorption isotherm of the sulfurimpregnated carbonaceous cotton prepared using $1.0 \mathrm{M}$ $\mathrm{Na}_{2} \mathrm{~S}$ and $1.0 \mathrm{M} \mathrm{K}_{2} \mathrm{~S}$. As the equilibrium concentration increased, the amount of nickel adsorption for both adsorbents increased and reached about $0.3 \mathrm{mmol} / \mathrm{g}$ and $0.2 \mathrm{mmol} / \mathrm{g}$ for the adsorbent using $\mathrm{Na}_{2} \mathrm{~S}$ and for $\mathrm{K}_{2} \mathrm{~S}$, respectively. The $\mathrm{pH}$ before adsorption was $5-7$ in each nickel concentration solution. After adsorption, $\mathrm{pH}$ increased to 7 - 10 when the adsorbent obtained using 
$\mathrm{Na}_{2} \mathrm{~S}$ was used, while $\mathrm{pH}$ decreased to around 3 when the adsorbent obtained using $\mathrm{K}_{2} \mathrm{~S}$ was used.

The nickel adsorption behavior of the adsorbent obtained using $1.0 \mathrm{M} \mathrm{Na}_{2} \mathrm{~S}$ and $1.0 \mathrm{M} \mathrm{K}_{2} \mathrm{~S}$ were determined by isotherm models. In several isotherm models, the Langmuir and Freundlich models were available to describe this experimental data.

The liner form of the Langmuir model is given by:

$$
\frac{\mathrm{C}_{\mathrm{e}}}{\mathrm{q}_{\mathrm{e}}}=\frac{1}{\mathrm{Q}_{\max } * \mathrm{~K}_{\mathrm{L}}}+\frac{\mathrm{C}_{\mathrm{e}}}{\mathrm{Q}_{\max }}
$$

where $\mathrm{Q}_{\max }(\mathrm{mmol} / \mathrm{g})$ and $\mathrm{K}_{\mathrm{L}}(\mathrm{L} / \mathrm{mmol})$ are Langmuir constants related to the maximum adsorption capacity corresponding to complete coverage of the available adsorption sites and a measure of adsorption energy (equilibrium adsorption constant), respectively. These constants were found from the slope and intercept of the linear plot of $\mathrm{C}_{\mathrm{e}} / \mathrm{q}_{\mathrm{e}}$ vs. $\mathrm{C}_{\mathrm{e}}$ so that $\mathrm{Q}_{\max }=1 /$ slope and $\mathrm{K}_{\mathrm{L}}=$ slope/intercept.

The linear form of the Freundlich model is also given by:

$$
\ln \left(\mathrm{q}_{\mathrm{e}}\right)=\ln \left(\mathrm{K}_{\mathrm{F}}\right)+\left(\frac{1}{\mathrm{n}}\right) * \ln \left(\mathrm{C}_{\mathrm{e}}\right)
$$

where $\mathrm{K}_{\mathrm{F}}$ and $\mathrm{n}$ are Freundlich constants determined from the slope and intercept of the plot of $\ln \left(\mathrm{q}_{\mathrm{e}}\right) \mathrm{vs}$. $\ln$ $\left(\mathrm{C}_{\mathrm{e}}\right)$.

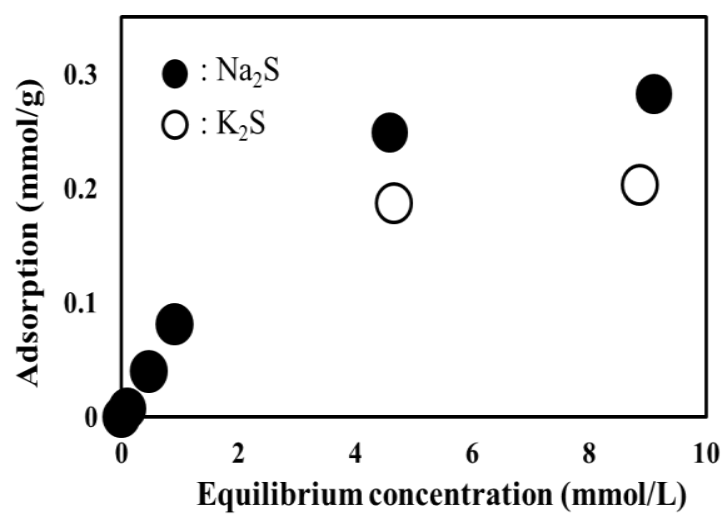

Figure 2 Isotherm for nickel using the powdered adsorbents prepared using $1.0 \mathrm{M} \mathrm{Na}_{2} \mathrm{~S}$ and $1.0 \mathrm{M} \mathrm{K}_{2} \mathrm{~S}$.

The Langmuir and Freundlich isotherm models were applied to the experimental data, and the obtained parameters calculated by each isotherm model are shown in Table 1. These experimental results provided a correlation regression coefficient $\left(\mathrm{R}^{2}\right)$ as a measure of the goodness-of-fit. Under both conditions, the Langmuir model matched the data better than the Freundlich model as the former had a higher correlation regression coefficient. The $\mathrm{Q}_{\max }$, as calculated from the Langmuir isotherm model the adsorbent obtained using
$\mathrm{Na}_{2} \mathrm{~S}$ was $0.43 \mathrm{mmol} / \mathrm{g}$, which was higher than that using $\mathrm{K}_{2} \mathrm{~S}(0.27 \mathrm{mmol} / \mathrm{g})$.

Table 1 Parameters and correlation regression using Langmuir and Freundlich models.

\begin{tabular}{c|c|c|c|c|c|c}
\hline & \multicolumn{3}{|c|}{ Langmuir } & \multicolumn{3}{c}{ Freundlich } \\
\hline & $\begin{array}{c}\mathrm{Q}_{\max } \\
(\mathrm{mmol} / \mathrm{g})\end{array}$ & $\begin{array}{c}\mathrm{K}_{\mathrm{L}} \\
(\mathrm{L} / \mathrm{mmol})\end{array}$ & $\mathrm{R}^{2}$ & $\mathrm{n}$ & $\mathrm{K}_{\mathrm{F}}$ & $\mathrm{R}^{2}$ \\
\hline $\mathrm{Na}_{2} \mathrm{~S}$ & 0.43 & 0.24 & 0.98 & 0.78 & 0.067 & 0.97 \\
\hline $\mathrm{K}_{2} \mathrm{~S}$ & 0.27 & 0.38 & 0.98 & 0.72 & 0.058 & 0.94 \\
\hline
\end{tabular}

Figure 3 shows that XRD patterns of the fibrous adsorbent obtained using $0.5 \mathrm{M} \mathrm{Na}_{2} \mathrm{~S}$ before and after adsorption. A broad peak was observed in the adsorbent before and after adsorption, and appears no new peaks after adsorption. It is noted that the same tendency was found for all samples.

Figure 4 shows that SEM images of the fibrous adsorbent obtained using $0.5 \mathrm{M} \mathrm{Na}_{2} \mathrm{~S}$ before and after adsorption. The same surface morphologies of the adsorbent before and after adsorption were observed. It is noted that nickel, which was not detected before adsorption, can be detected on the surface of the adsorbents after adsorption by EDS analysis, which means that nickel is adsorbed on the surface of the fibrous adsorbent. It is noted that same tendency was found for all samples.

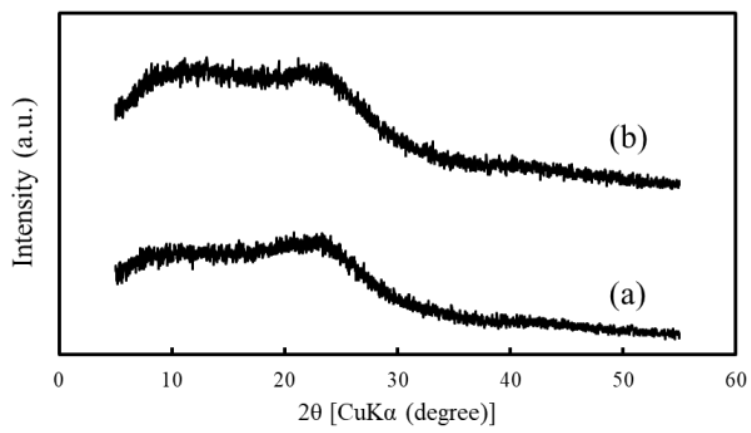

Figure 3 XRD patterns of the fibrous adsorbent obtained using $0.5 \mathrm{M} \mathrm{Na}_{2} \mathrm{~S}$ (a) before and (b) after adsorption.

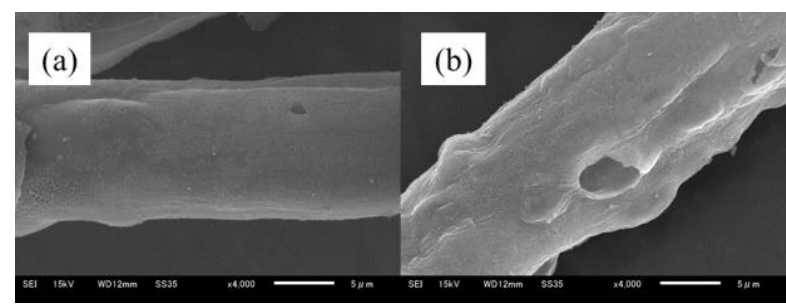

Figure 4 SEM images of the fibrous adsorbent obtained using $0.5 \mathrm{M} \mathrm{Na}_{2} \mathrm{~S}$ (a) before and (b) after adsorption. 


\section{Reduction treatment}

Figure 5 shows that XRD patterns of the nickel adsorbed fibrous cotton adsorbents obtained using $0.5 \mathrm{M} \mathrm{Na} 2 \mathrm{~S}$, 1.0 $\mathrm{M} \mathrm{Na}_{2} \mathrm{~S}, 0.5 \mathrm{M} \mathrm{K}_{2} \mathrm{~S}$ and $1.0 \mathrm{M} \mathrm{K}_{2} \mathrm{~S}$ after reduction at $1000{ }^{\circ} \mathrm{C}$. The peaks of $\mathrm{Ni}$ metal were confirmed on the adsorbent obtained using $0.5 \mathrm{M} \mathrm{Na} \mathrm{N}_{2} \mathrm{~S}$, while the peaks of $\mathrm{Ni}$ were not observed on the adsorbent using 1.0 $\mathrm{M} \mathrm{Na}_{2} \mathrm{~S}$. The peaks of $\mathrm{Ni}_{3} \mathrm{~S}_{2}$ were confirmed on the adsorbents obtained using $\mathrm{K}_{2} \mathrm{~S}$, while the adsorbent using 1.0 $\mathrm{M} \mathrm{Na}_{2} \mathrm{~S}$ has no peaks.

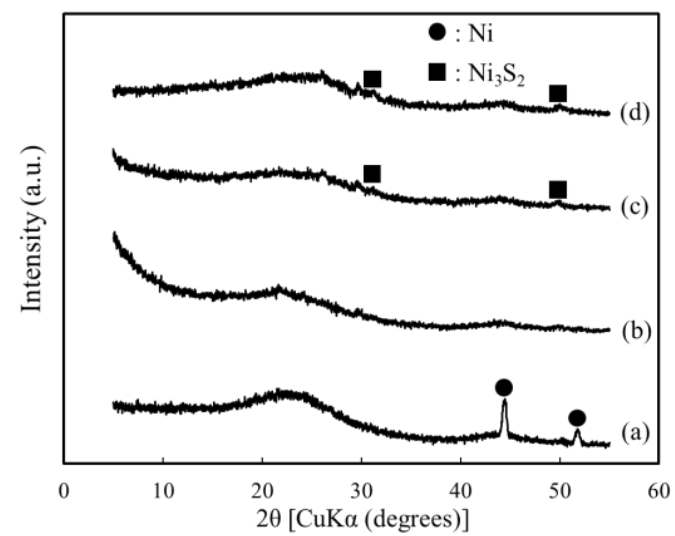

Figure 5 XRD patterns of the nickel adsorbed adsorbents after reduction at $1000{ }^{\circ} \mathrm{C}$ obtained using (a) $0.5 \mathrm{M} \mathrm{Na}_{2} \mathrm{~S}$, (b) $1.0 \mathrm{M} \mathrm{Na}_{2} \mathrm{~S}$, (c) $0.5 \mathrm{M} \mathrm{K}_{2} \mathrm{~S}$ and (d) $1.0 \mathrm{M} \mathrm{K}_{2} \mathrm{~S}$.

Figure 6 shows that SEM images of the nickel adsorbed adsorbents obtained using $0.5 \mathrm{M} \mathrm{Na}_{2} \mathrm{~S}, 1.0 \mathrm{M} \mathrm{Na}_{2} \mathrm{~S}, 0.5$ $\mathrm{M} \mathrm{K} \mathrm{K}_{2} \mathrm{~S}$ and $1.0 \mathrm{M} \mathrm{K} 2 \mathrm{~S}$ after reduction at $1000{ }^{\circ} \mathrm{C}$. Particles were observed on the surface of the adsorbents obtained using $0.5 \mathrm{M} \mathrm{Na}_{2} \mathrm{~S}, 0.5 \mathrm{M} \mathrm{K}_{2} \mathrm{~S}$ and $1.0 \mathrm{M} \mathrm{K}_{2} \mathrm{~S}$. It is noted that the particles on the adsorbents prepared using $\mathrm{K}_{2} \mathrm{~S}$ contained about $9-10 \%$ of nickel and about $3.5 \%$ of sulfur, while the particles on the adsorbent prepared using $0.5 \mathrm{M} \mathrm{Na}_{2} \mathrm{~S}$ contained $19.3 \%$ of nickel and $0.2 \%$ of sulfur.

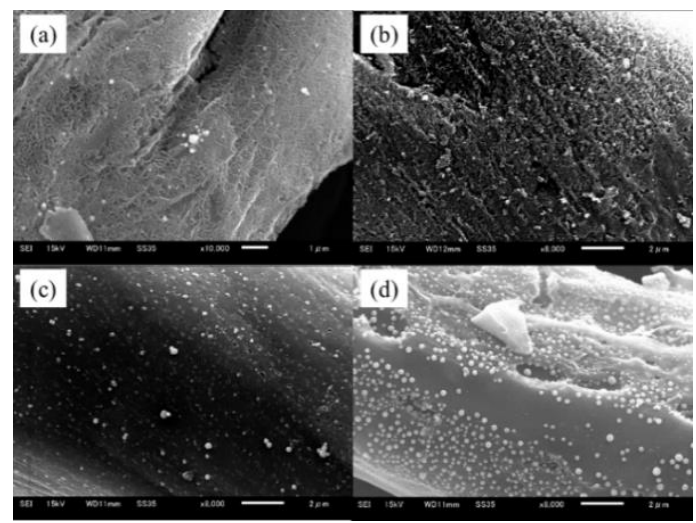

Figure 6 SEM images of the nickel adsorbed adsorbents after reduction at $1000{ }^{\circ} \mathrm{C}$ obtained using (a) $0.5 \mathrm{M} \mathrm{Na}_{2} \mathrm{~S}$, (b) $1.0 \mathrm{M} \mathrm{Na}_{2} \mathrm{~S}$, (c) $0.5 \mathrm{M} \mathrm{K}_{2} \mathrm{~S}$ and (d) $1.0 \mathrm{M} \mathrm{K}_{2} \mathrm{~S}$.

Figure 7 shows that XRD patterns of the nickel adsorbed adsorbents obtained using $0.5 \mathrm{M} \mathrm{Na}_{2} \mathrm{~S}$ after reduction at $400-1000{ }^{\circ} \mathrm{C}$. The peaks of $\mathrm{Ni}$ were observed after reduction at 800 and $1000{ }^{\circ} \mathrm{C}$, while no peaks after reduction at $400{ }^{\circ} \mathrm{C}$ and $600{ }^{\circ} \mathrm{C}$.

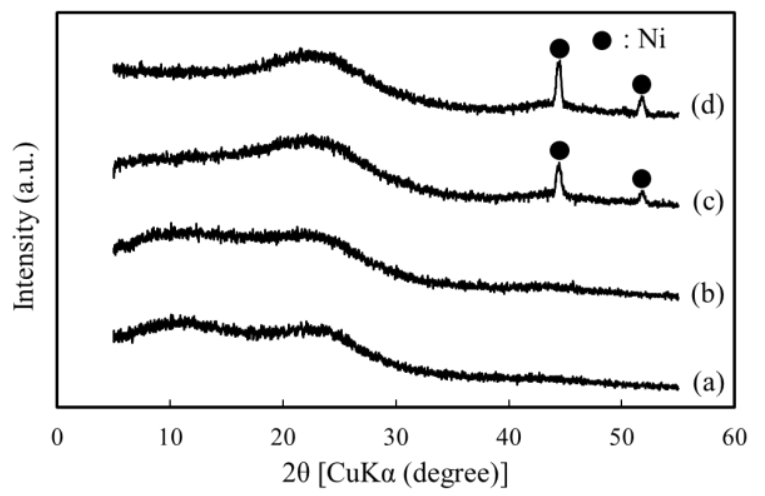

Figure 7 XRD patterns of the nickel adsorbed adsorbent obtained using $0.5 \mathrm{M} \mathrm{Na}_{2} \mathrm{~S}$ after reduction at (a) 400, (b) 600, (c) 800 and (d) $1000{ }^{\circ} \mathrm{C}$.

Figure 8 shows that SEM images of the nickel adsorbed adsorbents obtained using $0.5 \mathrm{M} \mathrm{Na}_{2} \mathrm{~S}$ after reduction at $400-1000{ }^{\circ} \mathrm{C}$. Particles were observed after reduction at 800 and $1000{ }^{\circ} \mathrm{C}$, while there were no particles on the surface of the adsorbents after reduction at 400 and 600 ${ }^{\circ} \mathrm{C}$. From EDS analysis, the particles are considered as nickel metal (Ni: $26.6 \mathrm{wt} \%, \mathrm{~S}: 0.2 \mathrm{wt} \%$ ). The amount and size of the particles on the surface of the adsorbent after reduction at $1000{ }^{\circ} \mathrm{C}$ was higher than that at $800{ }^{\circ} \mathrm{C}$.

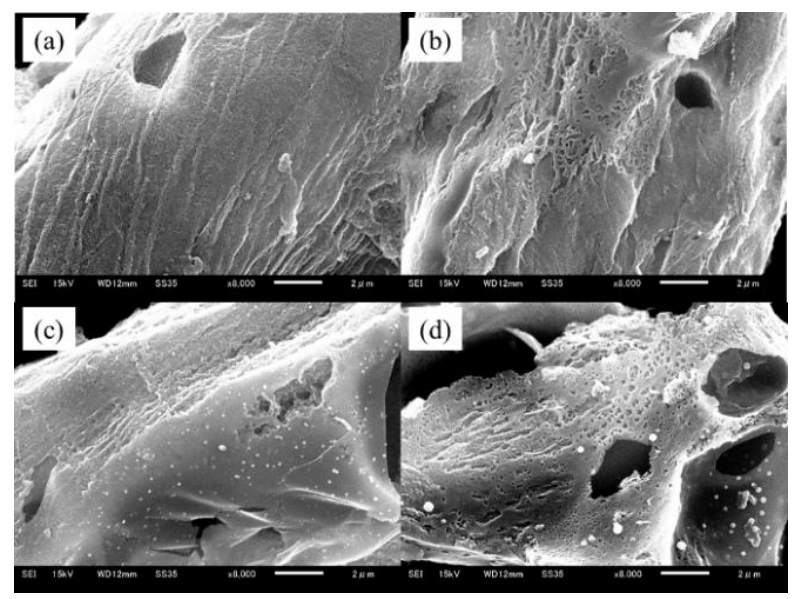

Figure 8 SEM images of the nickel adsorbed adsorbent obtained using $0.5 \mathrm{M} \mathrm{Na}_{2} \mathrm{~S}$ after reduction at (a) 400, (b) 600, (c) 800 and (d) $1000{ }^{\circ} \mathrm{C}$.

Figure 9 shows that XRD patterns of the fibrous adsorbents obtained using $1.0 \mathrm{M} \mathrm{K}_{2} \mathrm{~S}$ after reduction at 
$400-1000{ }^{\circ} \mathrm{C}$. The peaks of $\mathrm{Ni}_{3} \mathrm{~S}_{2}$ were observed after reduction at 800 and $1000{ }^{\circ} \mathrm{C}$, while no peaks after reduction at $400{ }^{\circ} \mathrm{C}$ and $600{ }^{\circ} \mathrm{C}$.

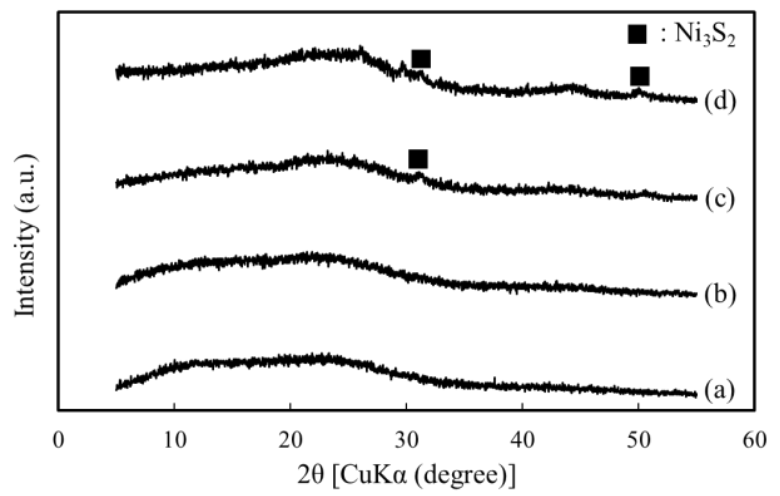

Figure 9 XRD patterns of the nickel adsorbed adsorbent obtained using 1.0 $\mathrm{M} \mathrm{K}_{2} \mathrm{~S}$ after reduction at (a) 400, (b) 600, (c) 800 and (d) $1000{ }^{\circ} \mathrm{C}$.

Figure 10 shows that SEM images of the nickel adsorbed adsorbents obtained using $1.0 \mathrm{M} \mathrm{K}_{2} \mathrm{~S}$ after reduction at $400-1000{ }^{\circ} \mathrm{C}$. Particles were obtained after reduction at 800 and $1000{ }^{\circ} \mathrm{C}$, while there were no particles on the surface after reduction at 400 and $600{ }^{\circ} \mathrm{C}$. From EDS analysis, the particles are considered as nickel sulfide (Ni: $9.9 \mathrm{wt} \%, \mathrm{~S}: 3.6 \mathrm{wt} \%$ ). The amount and size of the particles on the surface of the adsorbent after reduction at $1000{ }^{\circ} \mathrm{C}$ was higher than that at $800{ }^{\circ} \mathrm{C}$.

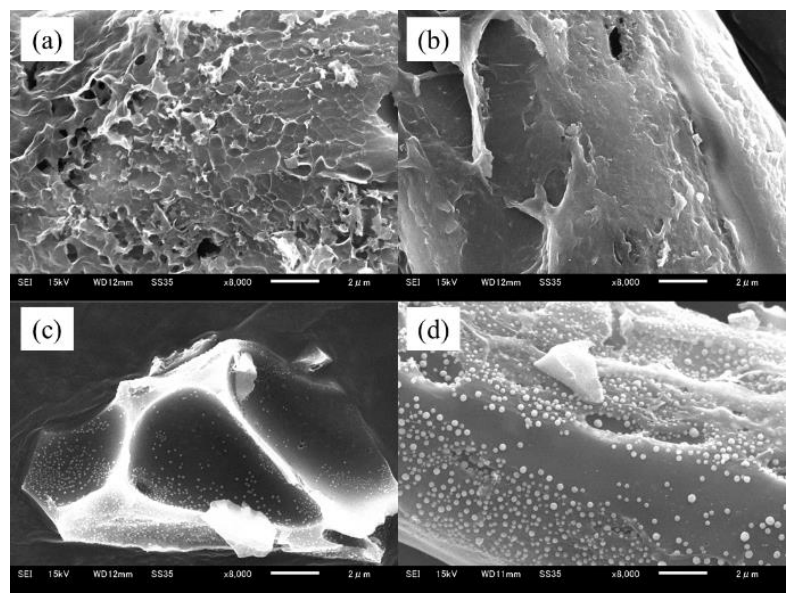

Figure 10 SEM images of the nickel adsorbed adsorbent obtained using 1.0 $\mathrm{M} \mathrm{K}_{2} \mathrm{~S}$ after reduction at (a) 400, (b) 600, (c) 800 and (d) $1000{ }^{\circ} \mathrm{C}$.

From these results, it is confirmed that nickel metal particles obtain on the surface of the adsorbent obtained using 0.5 M Na $2 \mathrm{~S}$, while nickel sulfide particles obtain on the adsorbent prepared using $\mathrm{K}_{2} \mathrm{~S}$, after reduction treatment. With increasing reduction temperature to 600 ${ }^{\circ} \mathrm{C}$, no new particles were confirmed on the adsorbent, above $800{ }^{\circ} \mathrm{C}$ nickel metal and nickel sulfide were observed.

\section{CONCLUSION}

Sulfur-impregnated carbonaceous cotton was prepared using $\mathrm{Na}_{2} \mathrm{~S}$ and $\mathrm{K}_{2} \mathrm{~S}$ solutions with $0.5 \mathrm{M}$ and $1.0 \mathrm{M}$, and then nickel was adsorbed on the cotton adsorbent. The equilibrium adsorption capacity of the adsorbents obtained using $\mathrm{Na}_{2} \mathrm{~S}$ and $\mathrm{K}_{2} \mathrm{~S}$ solutions for nickel ion were found to match the Langmuir isotherm better than Freundlich isotherm, and the calculated maximum adsorption capacity of the adsorbent obtained using $\mathrm{Na}_{2} \mathrm{~S}$ and $\mathrm{K}_{2} \mathrm{~S}$ were $0.43 \mathrm{mmol} / \mathrm{g}$ and $0.27 \mathrm{mmol} / \mathrm{g}$, respectively, which means that the adsorbent using $\mathrm{Na}_{2} \mathrm{~S}$ has higher nickel adsorption ability than the one using $\mathrm{K}_{2} \mathrm{~S}$. Nickel adsorbed on the adsorbent was precipitated by reduction treatment. $\mathrm{Ni}_{3} \mathrm{~S}_{2}$ crystals were precipitated on the adsorbent obtained using $1.0 \mathrm{M} \mathrm{K}_{2} \mathrm{~S}$, and nickel metal crystals were precipitated on the surface of the adsorbent using $0.5 \mathrm{M} \mathrm{Na}_{2} \mathrm{~S}$. The crystals of nickel metal and nickel sulfide could precipitate above $800{ }^{\circ} \mathrm{C}$, and as reduction temperature increased, the amount and size of the particles increased.

\section{ACKNOWLEDGEMENT}

This work was supported by the Chiba University SEEDS Fund (Chiba University Open Recruitment for International Exchange Program).

\section{REFERENCES}

[1] Fu, F., Xie, L., Tang, B., Wang, Q. and Jiang, S., 2012. Application of a novel strategy-advanced Fenton-chemical precipitation to the treatment of strong stability chelated heavy metal containing wastewater. Chemical Engineering Journal, 283, 189-190.

[2] Ahamad, T., Naushad and M., Inamuddin, 2015. Heavy metal ion-exchange kinetic studies over cellulose acetate $\mathrm{Zr}(\mathrm{IV})$ molybdophosphate composite cation exchanger. Desalination and Water Treatment, 53, 1675-1682.

[3] Pathania, D., Sharma, G., Naushad, M. and Kumar, A., 2014. Synthesis and characterization of a new nanocomposite cation exchanger polyacrylamide $\mathrm{Ce}(\mathrm{IV})$ silicophosphate: photocatalytic and antimicrobial applications. Journal of Industrial and Engineering Chemistry, 20, 3596-3603.

[4] Fang, X., Li, J., Li, X., Pan, S., Zhang, X., Sun, X., Shen, J., Han, W. and Wang, L., 2017. Internal pore decoration with polydopamine nanoparticle on polymeric ultrafiltration membrane for enhance heavy metal removal. Chemical Engineering. Journal, 314, 38-49. 
[5] Zhang, Q., Wang, N., Zhao, L., Xu, T. and Cheng, Y., 2013. Polyamidoamine dendronized hollow fiber membranes in the recovery of heavy metal ions, $A C S$ Applied Materials \& Interfaces, 5, 1907-1912.

[6] Alqadami, A., Naushad, M., Abdalla, A.M., Ahamad, T., Alothman, Z.A. and Alshehri, S.M., 2016. Synthesis and characterization of $\mathrm{Fe}_{3} \mathrm{O}_{4} @ \mathrm{TSC}$ nanocomposite: highly efficient removal of toxic metal ions from aqueous medium. RSC Advances, 6, 22679-22689.

[7] Alqadami, A.A., Naushad, M., Abdalla, M.A., Ahamad, T., ALOthman, Z.A., Alshehri, S.A. and Ghfar, A.A., 2017. Efficient removal of toxic metal ions from wastewater using a recyclable nanocomposite: a study of adsorption parameters and interaction mechanism. Journal of Cleaner Production, 156, 426-436.

[8] Cincotti, A., Lai, N., Orru, R. and Cao, G., 2001. Sardinian natural clinoptilolites for heavy metals and ammonium removal: experimental and modeling. Chemical Engineering Journal, 84, 275-282.

[9] Villaescusa, I., Martinez, M. and Miralles, N., 2000. Heavy metal uptake from aqueous solution by cork and yohimbe bark wastes. Journal of Chemical Technology and Biotechnology, 76, 812-816.

[10] Chamarthy, S., Seo, C.W. and Marshall, W.E., 2001. Adsorption of selected toxic metals by modified peanut shells. Journal of Chemical Technology and Biotechnology, 76, 593-597.

[11] Das, D.D., Mahapatra, R., Pradhan, J., Das, S.N. and Thakur, R.S., 2000. Removal of Cr(VI) from aqueous solution using activated cow dung carbon. Journal of Colloid and Interface Science, 232, 235240.

[12] Wajima, T., 2013. Removing lead ions from aqueous solutions with sulfur-impregnated adsorbents. Advanced Materials Research, 684, 198202.

[13] Wajima, T., 2013. Preparation of carbonaceous heavy metal adsorbent from paper sludge using sulfur impregnation. Proceedings of the 28th International Conference on Solid Waste Technology and Management, 630-638.

[14] Wajima, T., 2014. Preparation of adsorbent with lead removal ability using sulfur-impregnation. Advanced Materials Research, 831, 253-257.

[15] Wajima, T., 2014. Preparation of adsorbent with lead removal ability from paper sludge using sulfurimpregnation. APCBEE Procedia, 10, 164-169.

[16] Wajima, T., 2016. Preparation of carbonaceous adsorbent from rice straw using sulfur impregnation for nickel recovery from plating waste solution. Proceedings of the XXVIII International Mineral Processing Congress, 106.

[17] Wajima, T. and Sugawara, K., 2011. Adsorption behavior of mercury from aqueous solution using sulfur-impregnated adsorbent developed from coal. Fuel Processing Technology, 92, 1322-1327.

[18] Goel, J., Kadirvelu, K., Rajagopal, C. and Kumer, G.V., 2005. Removal of lead(II) by adsorption using treated granular activated carbon: batch and column studies. Journal of Hazardous Materials, 125, 211220.

[19] Yuan, C.-S., Lin, H.-Y., Wu, C.-H., Liu, M.-H. and Hung, C.-H., 2004. Preparation of sulfurized powdered activated carbon from waste tire using an innovative compositive impregnation process. Journal of the Air and Waste Management Association, 54, 862-870.

[20] Iguchi M. and Wajima T., 2018. Preparation of sulfur-impregnated carbonaceous filter with high heavy metal adsorption capacity. Journal of ion exchange, 29, 153-157

[21] Pearson, R.G., 1963. Hard and soft acids and bases. Journal of the American Chemical Society, 85, 35333539.

[22] Pearson, R.G., 1987. Recent advances in the concept of hard and soft acids and bases. Journal of Chemical Education, 64, 561-567.

[23] USGS, 2017. Mineral Commodity Summaries 2017 U.S., Geological Survey Reston, VA. 